\title{
ACUTE ZONAL OCCULT OUTER RETINOPATHY (AZOOR) ASSOCIATED WITH MULTIFOCAL CHOROIDOPATHY
}

\author{
F. G. HOLZ, R. Y. KIM, S. D. SCHWARTZ, C. A. HARPER, J. WROBLEWSKI, G. B. ARDEN \\ and A. C. BIRD \\ London
}

\begin{abstract}
SUMMARY
Acute zonal occult outer retinopathy (AZOOR) may be precipitated by various retinal disorders and is characterised by rapid loss of visual field which cannot be explained by the ophthalmoscopic changes consequent upon the initiating disease. The electroretinogram is abnormal, indicating that the field loss is due to retinal dysfunction. The phenomenon was first recognised in the multiple evanescent white dot syndrome (MEWDS) as the enlarged blind spot syndrome. It was subsequently described with multifocal inner choroidopathy and acute macular neuropathy (AMN). We have identified 7 patients who presented with widespread visual loss associated with multifocal inner choroidopathy in whom functional loss was documented with electroretinography and automated visual field testing. All patients were young, myopic, and otherwise healthy women. Initial photopsia was noted by 4 patients. Fundus findings included scattered small partially pigmented yellowish lesions resembling those in multifocal inner choroidopathy or pseudo presumed ocular histoplasmosis syndrome, disc swelling, vitritis, and secondary choroidal neovascularisation. Two patients had bilateral involvement. All patients had an enlargement of the blind spot, and widespread visual field loss which was not explained by fundus changes. All had an abnormal electroretinogram suggesting widespread retinal disease. In AZOOR retinal dysfunction occurs without corresponding visible retinal lesions. This disorder appears to be precipitated by several conditions, although the causal relationship between the initiating event and the widespread functional loss is unknown.
\end{abstract}

Acute zonal occult outer retinopathy (AZOOR) was recently described by Gass ${ }^{1}$ as a clinical syndrome characterised by (1) acute loss of outer retinal function, involving one or both eyes of predominantly young women,

From: Department of Clinical Ophthalmology, Moorfields Eye Hospital and Institute of Ophthalmology, London, UK.

Correspondence to: Professor Alan C. Bird, FRCS, Department of Clinical Ophthalmology, Moorfields Eye Hospital, City Road, London EC1V 2PD, UK. Fax: 071-2519350.

Eye (1994) 8, 77-83 C 1994 Royal College of Ophthalmologists usually associated with photopsia, (2) minimal or no fundus changes initially, and (3) electroretinographic abnormalities. The field loss may not recover and fundus changes appropriate to the field loss may appear. The phenomenon of retinal dysfunction without corresponding ophthalmoscopic changes was first recognised in the multiple evanescent white dot syndrome (MEWDS) as the enlarged blind spot syndrome. ${ }^{2-4}$ It was subsequently described with multifocal inner choroidopathy, or pseudo presumed ocular histoplasmosis syndrome, ${ }^{5,6}$ and acute macular neuroretinopathy.

We describe 7 patients who presented to Moorfields Eye Hospital between December 1989 and April 1993 who developed visual loss not explained by fundus findings associated with multifocal fundus lesions resembling punctate inner choroidopathy.

\section{PATIENTS}

\section{Case 1}

A 25-year-old myopic woman presented in April 1992 with a 1 week history of flickering sensation - like 'jagged lines moving from the temporal to the nasal periphery' - initially white then grey in colour in her left eye visual field. She denied any other systemic complaints. Visual acuity was $6 / 5$ with each eye. She had few vitreous cells in the left eye. There were numerous scattered yellowish lesions at the level of inner choroid and retinal pigment epithelium as well as disc swelling (Fig. la,b). Three days later she noticed additional distortion and worsening flickering light sensations. Four weeks after the initial presentation she complained of trouble reading letters with her left eye. She had an episode of weakness associated with pain and coldness in both lower extremities for about 12 hours. Visual acuity with the left eye was now $6 / 36$ with eccentric fixation and $3+$ cells were seen in the vitreous. Perimetry showed severe visual field loss (Fig. 1c). Fluorescein angiography demonstrated juxtafoveal choroidal neovascularisation in the left eye. Full blood count, erythrocyte sedimentation rate, measurement of electrolytes and angiotensin converting enzyme, and a chest radiograph and a CT scan of the head were normal. 
Treatment with oral prednisolone $(80 \mathrm{mg} /$ day $)$ was initiated, and there was subjective improvement of the visual field, which was confirmed on perimetry. In June 1992 visual acuity was $1 / 60$ with the left eye, the vitritis had regressed, there was less disc swelling, and a hypertrophic scar had formed at the fovea (Fig. 1d).

Electroretinography in May 1992 revealed markedly abnormal rod and cone responses in the left eye. The scotopic amplitudes were reduced by $65 \%$ and the photopic

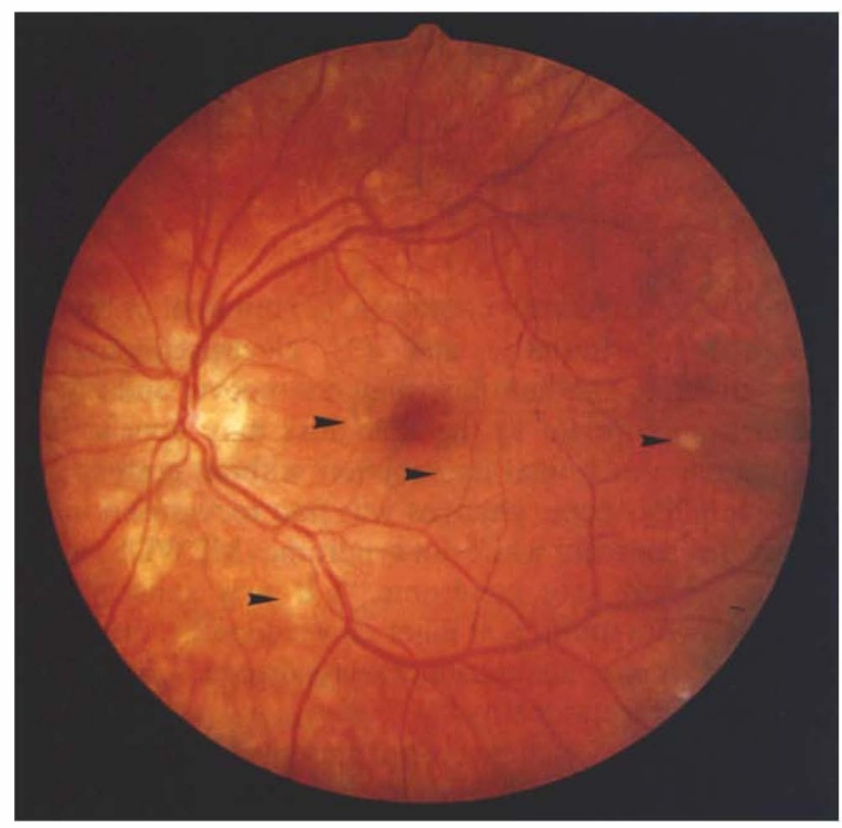

(a)

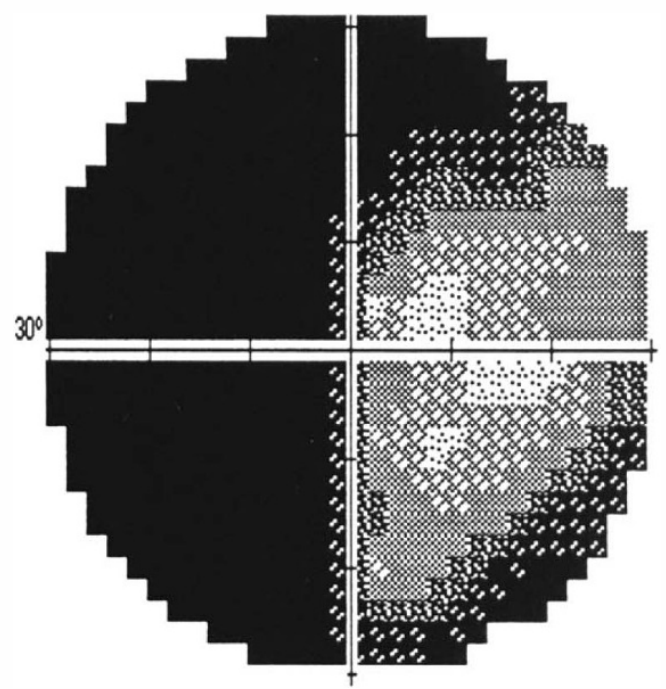

(c) by $50 \%$ when compared with the right eye. The oscillatory potentials and the flicker responses were extinguished. The electro-oculogram (EOG) was normal in the right (Arden index 225\%) and grossly abnormal (40\%) in the left eye. In June 1993 visual acuity was 2/60 with the left eye and there was no evidence for active inflammation. Automated field testing showed a persistent field loss. Electroretinography at this time indicated a slight further depression of function. There was no detectable A-wave

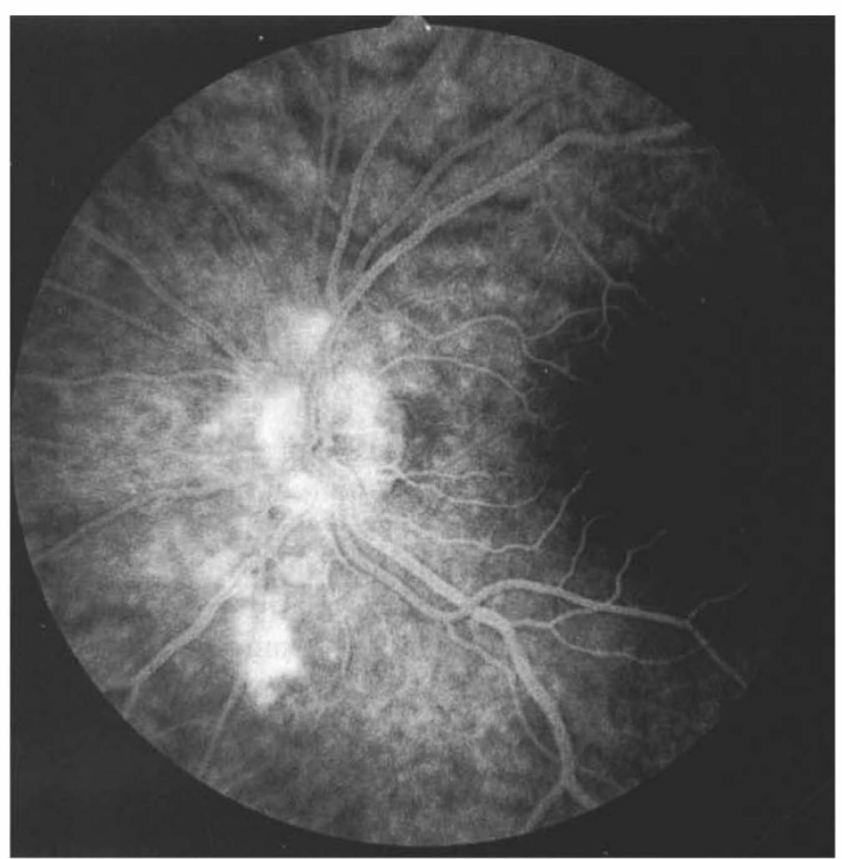

(b)

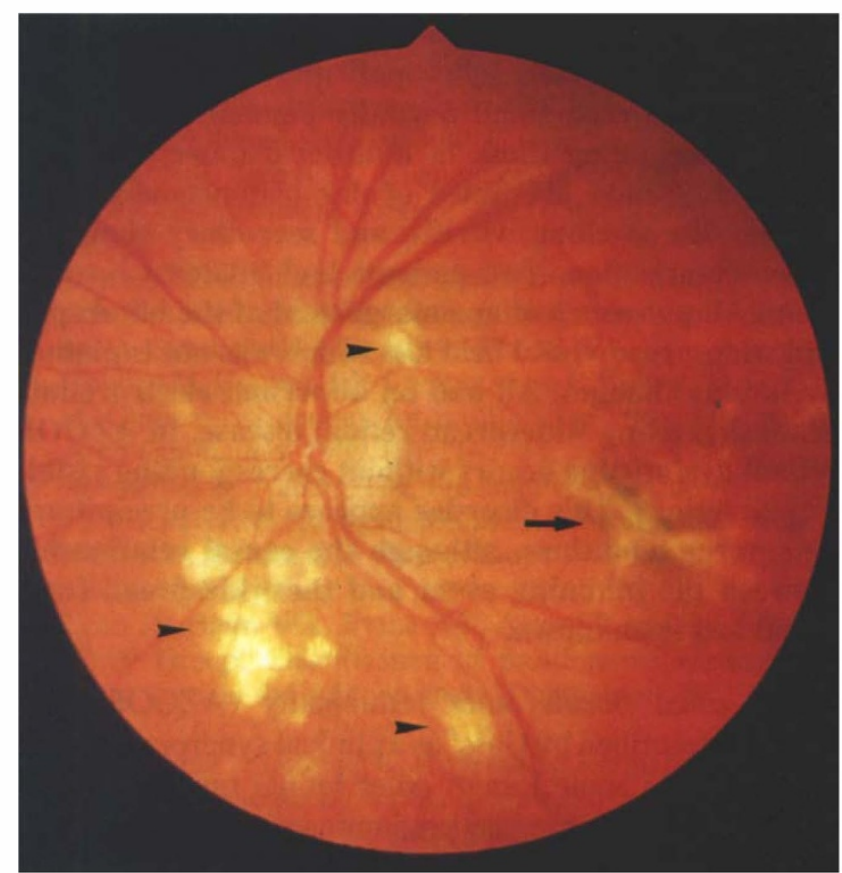

$(d)$

Fig. 1. Case 1, left eye. (a) Fundus 2 months after initial symptoms with scattered yellowish lesions (arrowheads); visual acuity 6/5. (b) Fluorescein angiogram 2 months after initial symptoms with hyperfluorescence of variable degree at the focal lesions. (c) Humphrey automated 30-2 visual field 8 months after initial presentation. (d) Eleven months after initial presentation. Visual acuity 4/60. Note the subretinal fibrosis (arrow') secondary to choroidal neovascularisation, and depigmented, atrophic lesions (arrowheads). 
on the maximal scotopic blue stimulus, the B-wave amplitude was smaller and the cone responses were extinguished (Fig. 4a).

\section{Case 2}

A 28-year-old myopic woman presented in January 1993 with gradual deterioration in her right eye vision. She denied any photopsia. There was peripapillary atrophy, multiple yellowish punched-out lesions throughout the posterior pole both nasal and temporal to the optic nerve, and in the central macula a flat scar. The left fundus was normal. By March 1993 she felt that her symptoms were no longer progressive. Visual acuity was $6 / 36$ with the right and $6 / 6$ with the left eye. The fundus lesions in the right eye appeared to be unchanged. Automated field testing demonstrated an enlarged blind spot and a superior scotoma in the right eye. The electroretinogram showed reduced rod and markedly abnormal cone responses in the right eye: the rod B-wave was delayed (implicit time $60 \mathrm{~ms}$ ) and slightly reduced (amplitude $230 \mu \mathrm{V}$ ). The $30 \mathrm{~Hz}$ flicker amplitudes were about half the size of the left eye. A chest radiograph, VDRL test, TPHA test and the level of angiotensin converting enzyme were normal.

\section{Case 3}

A 23-year-old myopic woman complained of a 3 month history of photopsia with subsequent development of blurred vision associated with a partial loss of the temporal field in the left eye during one week in January 1993. Visual acuity was $6 / 6$ with the right eye and $6 / 24$ with the left. There were cells in the anterior chamber and vitreous. Funduscopy showed peripapillary scarring in the right eye and disc swelling and multiple punched-out small yellowish lesions. Inferior to the left disc and near the fovea two small creamy lesions at the level of inner choroid and retinal pigment epithelium were seen which appeared to represent active lesions (Fig. 2a, b). Automated field testing showed an enlarged blind spot and an adjacent superior scotoma in the left eye.

Electroretinography 3 months after the initial symptoms indicated an abnormal rod and cone response. The amplitude of the weaker blue flash scotopic electroretinogram was grossly reduced in the left eye, but with more intense stimuli the amplitude became similar to that of the right eye. The flicker amplitudes were within normal limits but lower in the left than in the right eye, being reduced by almost half and markedly delayed in the left eye. An orbital floor injection of $40 \mathrm{mg}$ betamethasone was administered. Two months later visual acuity improved to $6 / 12$, but the extent and depth of field loss remained unchanged (Fig. 2c). An electroretinogram in May 1993 showed a slight progression of the abnormalities in both rod and cone responses. Symptoms further regressed, and by May 1993 visual acuity was 6/9, there were no cells in the anterior chamber and few cells in the left vitreous.

\section{Case 4}

A 16-year-old myopic woman was seen after her optician noticed abnormal findings in her right fundus. At that time her visual acuity was $6 / 18$ with the right and $6 / 5$ with the left eye. She noted progressive deterioration in the right eye during the following 4 years. In December 1992 visual acuity was $6 / 60$ with the right eye. There were vitreous cells, multiple punched-out atrophic lesions with variable pigmentary reaction, peripapillary scarring and a linear chorioretinal scar in the inferotemporal equatorial region of the right eye resembling linear streak lesions described in presumed ocular histoplasmosis syndrome (Fig. 3) ${ }^{8}$ No active lesions were noted. The left fundus was normal.

Electroretinography at this time showed a 50\% reduction in rod amplitudes, and a delay in the $30 \mathrm{~Hz}$ flicker by $40 \%$, indicating abnormal cone function (Fig. 4b). Automated field testing showed diffuse depression of sensitivity, an enlarged blind spot and superior and inferior scotomas. In April 1993 electroretinography again indicated grossly abnormal right eye scotopic responses, abnormal oscillatory potentials and delayed flicker responses. A pattern electroretinogram obtained at this time was also grossly abnormal in the right eye. The visual field loss was unchanged.

\section{Case 5}

A 23-year-old myopic woman presented with sudden onset of blurring of her left central vision in November 1991. On examination at that time visual acuity was $6 / 4$ with the right eye and $6 / 6$ with the left. In the left fundus were a few punched-out spots of chorioretinal atrophy and some pigmentary disturbance at the fovea. The patient subsequently developed greyish active lesions in the inner choroid both nasal to the disc and at the left macula, with an increase in her central visual distortion. In February 1992 visual acuity was $6 / 6$ with the right eye and 6/12 with the left. In addition to the previously noted punched-out lesions there was subretinal fibrosis extending under the left fovea, presumably a consequence of choroidal neovascularisation. Field testing showed an enlarged blind spot as well as central and paracentral loss. Electrodiagnostic testing in June 1993 revealed abnormal rod and cone responses. The rod B-wave in the left eye was markedly delayed at lower stimulus intensities, but became similar to the right at maximal stimulus intensity. The cone response was within normal limits but there was a $15 \%$ reduction in the amplitude when compared with the left eye. The EOG was normal in each eye (Arden index 248\% in the right and $239 \%$ in the left eye).

\section{Case 6}

A 37-year-old myopic female patient presented in April 1993 with a 3 week history of blurred central vision and a sensation of 'coloured lights' in her left eye visual field. The visual acuity was $6 / 6$ with the right eye and $6 / 24$ with the left, and there were a few cells in the left eye vitreous but none in the anterior chamber. There were small yellowish lesions at the level of the inner choroid close to the left fovea as well as numerous atrophic, partially pigmented scars in the mid-periphery. The right fundus was 


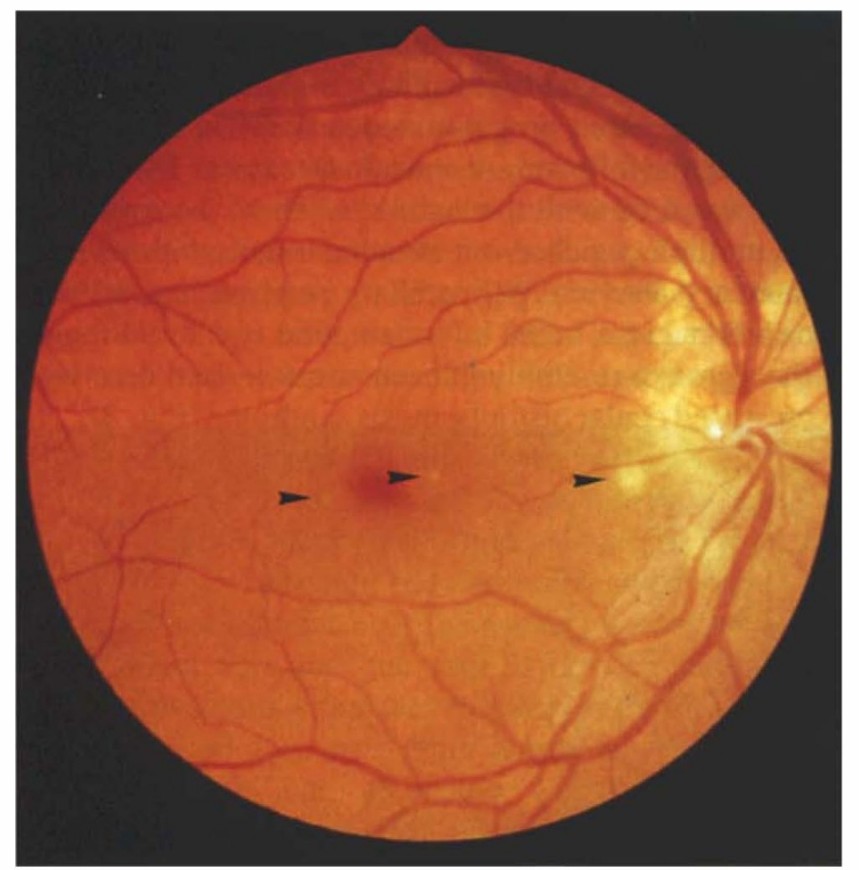

(a)

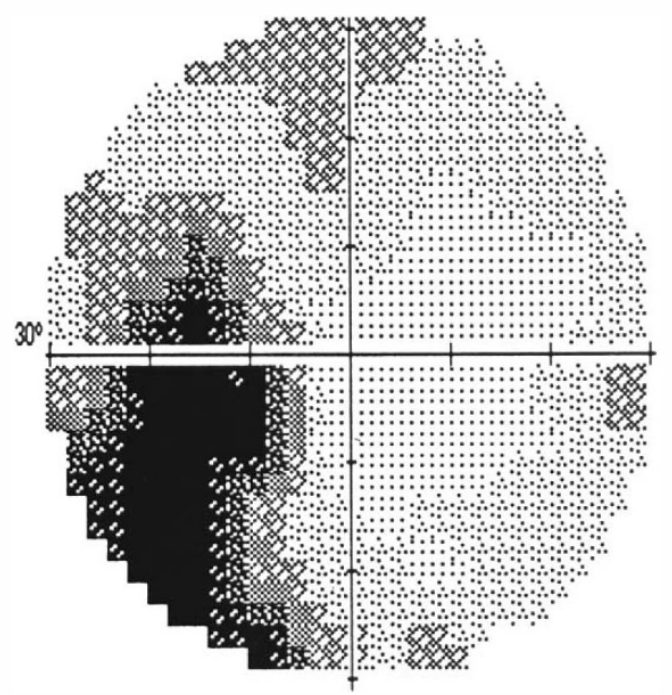

(c)

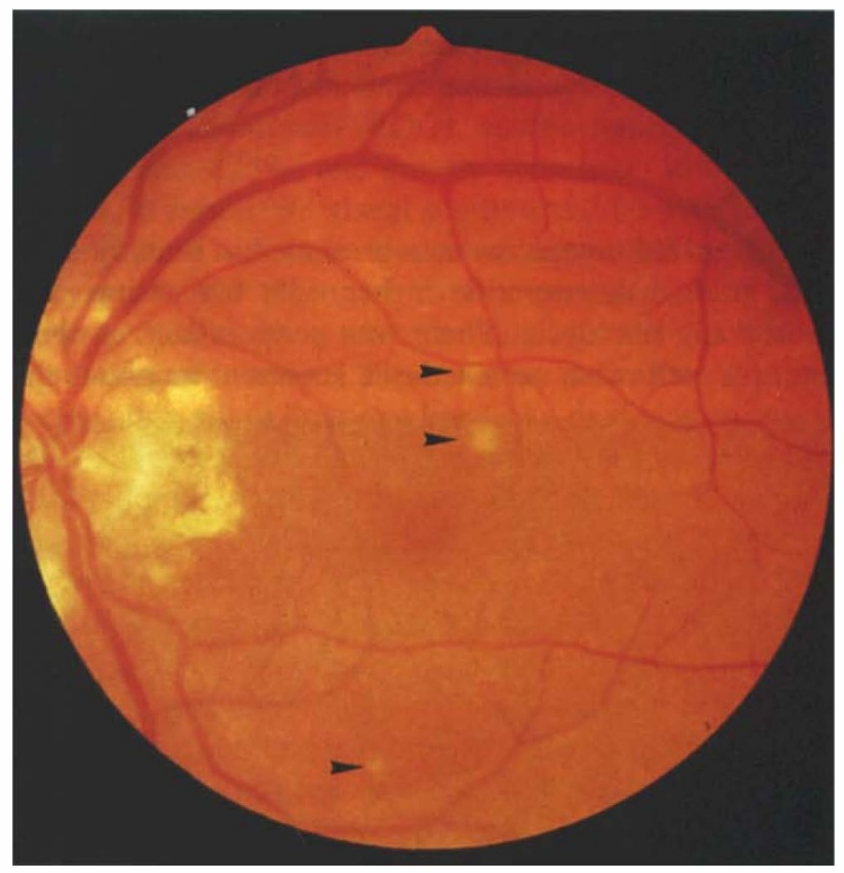

(b)

Fig. 2. Case 3. Right eye, visual acuity 6/6. Note the multiple yellowish lesions at the level of the inner choroid and the retinal pigment epithelium (arrowheads). (b) Left eye, visual acuity 6/24. Symptomatic eye 4 months after initial presentation. Note the multifocal yellowish lesions (arrowheads) and peripapillary scarring. (c) Humphrey automated 30-2 visual field 2 months after initial symptoms with enlargement of the blind spot and inferior-temporal scotoma in the left eye.

Fig. 3. Case 4, right eye. Curvilinear scar in the equatorial region at initial presentation. 


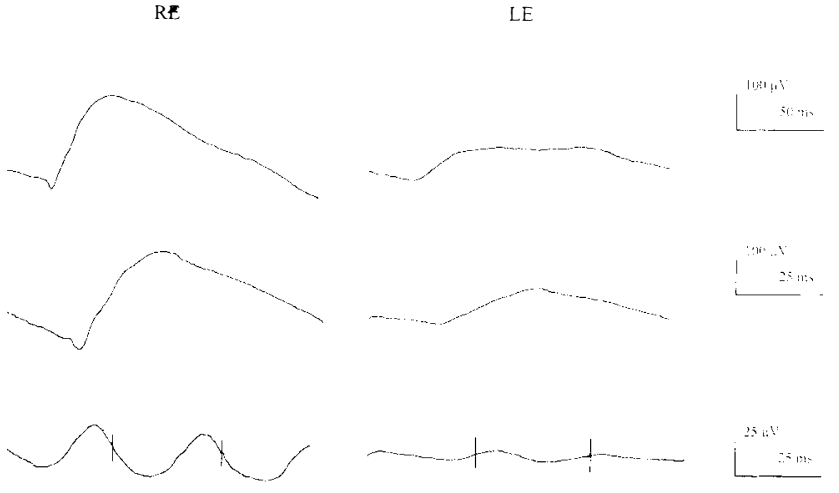

(a)

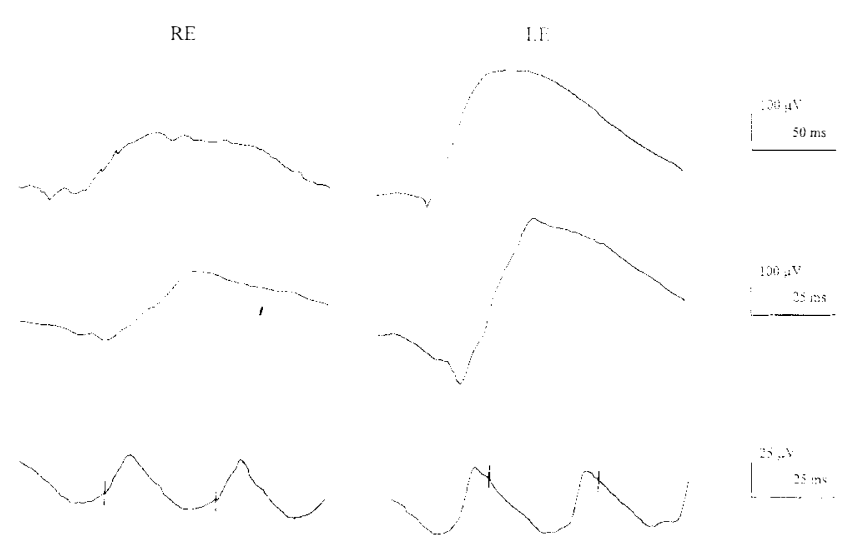

(b)

Fig. 4. Representative electroretinograms. Top row, blue $460 \mathrm{~nm}$ flash, maximal intensity; middle row, intense red $660 \mathrm{~nm}$ flash; bottom row, $30 \mathrm{~Hz}$ flicker. RE, right eve; LE, left eve. (a) Case 1. The electroretinogram was grossly abnormal in the left eve for every testing condition when compared with the right eye, which showed normal responses. (b) Case 4. The right eye showed a markedly delayed flicker response and reduced amplitudes to intense blue and red stimulus. The responses in the left eye were within normal limits.

normal. Automated field testing showed an enlarged blind spot and a central and paracentral scotoma in the left eye. A standard electroretinogram 1 month after the initial symptoms was within normal limits, but the rod A- and B-wave amplitudes were $25 \%$ lower in the left than in the right eye. The $30 \mathrm{~Hz}$ flicker response showed equal implicit times in each eye, although the amplitudes in the left eye were reduced by $20 \%$. These findings were interpreted as indicating a mild rod and cone functional loss in the left eye. The EOG showed a normal light rise in each eye (223\% in the right and 239\% in the left eye). The central and paracentral lesions subsequently evolved to depigmented scars without evidence for subretinal fluid accumulation on fluorescein angiography. The left eye visual acuity in June 1993 improved by one line to 6/18. A chest radiograph, angiotensin converting enzyme, and VDRL and TPHA tests were normal.

\section{Case 7}

A 32-year-old myopic woman presented with blurred vision and flickering lights in her left eye in February 1992. Her visual acuity was $6 / 5$ with the right eye and $6 / 12$ with the left. She had several yellowish atrophic spots at the posterior pole of the right eye and a single spot superior temporal to the right fovea. In the left eye similar lesions were seen in the posterior pole, there was mild disc swelling and vitreous cells. In the left eye she had a slightly enlarged blind spot, a paracentral and superior mid-peripheral scotoma. The EOG was abnormal in the left eye. The electroretinogram in June 1993 showed grossly reduced A- and B-wave amplitudes from the left eye in response to weak blue stimuli, but with more intense light the amplitudes were within normal limits. The flicker electroretinogram and visual evoked response were normal. One month later the patient noticed spontaneous improvement of her symptoms. Flickering sensations persisted for 2 more months. However, in September 1992 she complained of increased blurriness in her left eye. Fundus examination appeared unchanged. Four months later, visual acuity had returned to $6 / 6$ in the left eye; however, visual field defects persisted. Full blood count, erythrocyte sedimentation rate, CT scans of the head and orbits and a neurological evaluation were normal.

\section{DISCUSSION}

The clinical setting of the widespread retinal dysfunction was similar in all our cases, and was in excess of that which would have been expected from the limited nature of the visible fundus disease. All affected patients were young, healthy, myopic females who presented with acute or subacute unilateral visual loss (Table I). Photopsia was noted by 4 patients, and 2 gave a history of a viral-like illness before or during the clinical course. In 5 patients there were inflammatory cells present in the vitreous cells and in 2 in the anterior chamber. Evidence for optic disc oedema on funduscopy and fluorescein angiography was found in 4 patients. All patients had or developed small multifocal chorioretinal scars resembling lesions in punctate inner choroidopathy. In 2 patients these lesions occurred bilaterally. Two patients developed choroidal neovascularisation compromising central vision. All had enlargement of the blind spot and additional scotomas not corresponding with the fundus lesions. All had abnormal electroretinograms in the affected eye to varying degrees. During follow-up visual acuity improved in 3 patients, deteriorated further in 3 patients, and stayed the same in 1 patient. Of the patients with serial fields and electroretinogram testing the extent and depth of the visual field loss improved in 2 patients and was unchanged in one patient; the electroretinogram improved in 1, worsened in 1, and remained unchanged in 1 .

Numerous series of patients with similar multifocal fundus lesions have led to various descriptive terms that incorporate major features of the disease including 'multifocal inner choroiditis', 'recurrent multifocal choroiditis', 'multifocal choroiditis and panuveitis'," 'multifocal choroiditis', ${ }^{12-1+}$ 'progressive subretinal fibrosis and uveitis', 15 'punctate inner choroidopathy', ${ }^{16}$ 'haemorrhagic maculopathy, ${ }^{17}$ 'presumed ocular histo- 
Table I. Summary of clinical data

\begin{tabular}{|c|c|c|c|c|c|c|c|c|c|c|c|c|c|c|}
\hline \multirow[b]{2}{*}{ Case } & \multirow[b]{2}{*}{$\begin{array}{l}\text { Age } \\
(\mathrm{yr})\end{array}$} & \multicolumn{2}{|c|}{ Symptoms } & \multirow[b]{2}{*}{ VA } & \multirow[b]{2}{*}{$\begin{array}{l}\mathrm{A} / \mathrm{C} \\
\text { cells }\end{array}$} & \multirow[b]{2}{*}{$\begin{array}{l}\text { Vitreous } \\
\text { cells }\end{array}$} & \multirow[b]{2}{*}{$\begin{array}{l}\text { Focal } \\
\text { lesions }\end{array}$} & \multirow[b]{2}{*}{$\begin{array}{c}\text { Disc } \\
\text { oedema }\end{array}$} & \multirow[b]{2}{*}{ SRNV } & \multicolumn{2}{|c|}{ Visual field } & \multirow[b]{2}{*}{ ERG } & \multirow[b]{2}{*}{$\begin{array}{c}\text { EOG } \\
\text { Arden index }\end{array}$} & \multirow[b]{2}{*}{$\begin{array}{l}\text { Follow-up } \\
\text { (months) }\end{array}$} \\
\hline & & Photopsia & General & & & & & & & EBS & $\begin{array}{l}\text { Add. } \\
\text { scotoma }\end{array}$ & & & \\
\hline 1 & 25 & + & + & $\begin{array}{l}\text { R } 6 / 5, \\
\text { L } 6 / 5\end{array}$ & $1+$ & $3+$ & $\begin{array}{c}+ \\
\text { (Unilateral) }\end{array}$ & + & + & + & + & L ab. & $\begin{array}{l}\text { R } 222 \% \\
\text { I. } 40 \%\end{array}$ & 14 \\
\hline 2 & 28 & - & - & $\begin{array}{l}\text { R 6/36, } \\
\text { L 6/6 }\end{array}$ & - & - & + & - & - & + & + & $\mathrm{R} a b$. & ND & 6 \\
\hline 3 & 23 & + & - & $\begin{array}{l}\text { R 6/6, } \\
\text { L } 6 / 24\end{array}$ & $1+$ & $2+$ & (Unilateral) & + & - & + & + & $\mathrm{L} a b$. & ND & 6 \\
\hline 4 & 20 & - & - & $\begin{array}{l}\text { R } 6 / 18 \\
\text { L } 6 / 5\end{array}$ & - & $1+$ & $\stackrel{+}{+}$ & - & - & + & + & $\mathrm{R} a b$. & ND & 51 \\
\hline 5 & 23 & - & - & $\begin{array}{l}\text { R } 6 / 4 \\
\text { L } 6 / 6\end{array}$ & - & - & $\begin{array}{c}+ \\
\text { (Unilateral) }\end{array}$ & + & + & + & + & L ab. & $\begin{array}{l}\text { R } 248 \% \\
\text { L 239\% }\end{array}$ & 19 \\
\hline 6 & 37 & + & - & $\begin{array}{l}\text { R 6/6, } \\
\text { L 6/24 }\end{array}$ & - & $1+$ & $\stackrel{+}{+}$ & - & - & + & + & L ab. & $\begin{array}{l}\text { R 223\% } \\
\text { L 239\% }\end{array}$ & 3 \\
\hline 7 & 32 & + & + & $\begin{array}{l}\text { R 6/5, } \\
\text { L 6/12 }\end{array}$ & - & $1+$ & $\stackrel{+}{+}$ & + & - & + & + & $\mathrm{L} a b$. & $\begin{array}{l}\text { R } 199 \% \\
\text { L } 175 \%\end{array}$ & 16 \\
\hline
\end{tabular}

All patients were female and myopic.

VA, visual acuity at initial presentation; R, right; L. left: A/C. anterior chamber; SRNV, subretinal neovascularisation: EBS. enlargement of the blind spot; add., additional; ERG, electroretinogram: ab., abnormal: EOG. electro-oculogram: ND. not done.

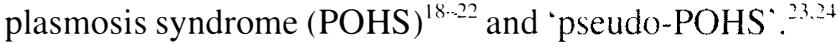
In almost all these series, as in ours, there is a preponderance of young (second or third decade), moderately myopic, healthy women. Why patients with those characteristics are at higher risk for developing such lesions is not understood. Although a viral aetiology, ${ }^{25.26}$ hormonal factors, Histoplasma capsulatum ${ }^{27}$ and bacteraemia $^{28}$ have been suggested, the cause remains obscure. It has also been suggested that all these appearances may have a common underlying aetiology, and describe various modes of presentation of a single disease. ${ }^{5}$

In the majority of the abovementioned series formal visual field testing or electrodiagnostic testing was not reported, so that the frequency of widespread functional loss in these multifocal diseases is unknown. A few reports describe extensive field loss associated with no or minimal fundus changes., ${ }^{2.5 .7}$ The first comprehensive description was by Gass ${ }^{1}$ who described 13 patients, again predominantly young women, who had visual field loss, photopsia, and minimal fundus changes in one or both eyes, in whom electroretinographic studies implied widespread retinal dysfunction. He introduced the descriptive term 'acute zonal occult outer retinopathy' (AZOOR) to characterise this syndrome. Six of his patients had evidence of bilateral involvement at the time of presentation, and 2 of those were asymptomatic in one eye. Three patients had delayed involvement of the fellow eye. Some of his patients had no focal fundus lesions when the visual field loss was detected whilst others had multifocal lesions resembling those in MEWDS or pseudo-POHS. It is possible that in those without fundus changes the functional loss was precipitated by MEWDS, since the clinical signs resolve rapidly. He observed depigmentation of the retinal pigment epithelium corresponding with the visual loss if it was persistent. The mean follow-up time was $34 \pm 5.2$ months, whereas the follow-up in our series was less (19 \pm 3.1 months). We have not observed widespread pigment epithelial changes in the area of field loss, but this may develop later on. All our patients had multifocal disease on funduscopy at first presentation resembling punctate inner choroidopathy, as opposed to the multiple clinical settings described by Gass.'

It appears that the phenomenon of visual loss due to retinal dysfunction but without corresponding funduscopic changes occurs in association with several clinical entities affecting the retina and choroid. The lack of ophthalmoscopic changes and the recovery of function, in at least some cases, implies that cell death does not occur early in the disorder.

One of our patients had an extremely low Arden index in the EOG of $40 \%$ (case 1). This could be explained on the basis of the standing potential across the retinal pigment epithelium being grossly reduced; interference by the increased light rise in the unaffected eye could cause such a gradient. The EOG electrodes across one eye are not electrically isolated from electrical currents produced in the other eye. As the eyes move, the EOG voltage from one eye slightly reduces the measured voltage from the other ('cross-talk'). Hence if one eye has no light rise, the increase in current during the light rise from the other eye produces a spurious fall, i.e. a ratio of less than $100 \%$. This is often seen in detachment, when ratios of $80-90 \%$ are observable. What relevance this has to the disorder is uncertain since similar abnormalities were not seen in the other cases, although the patient in question had the most severe disease.

The mechanism leading to malfunctioning of the retinal receptor-pigment epithelial cell complex in AZOOR, and the causal relationship between the initiating event and the widespread functional loss, are unknown. It has been sug- 
gested thaf, in the absence of fundus and fluorescein angiographic abnormalities, intracellular enzyme systems may be affected by immunological or toxic mechanisms precipitated possibly by a virus. ${ }^{1}$ This hypothesis is somewhat speculative, although the lack of ophthalmoscopic signs implies that dysfunction is not due to cell death early in the course of the disorder. Even if the pathogenesis of the cellular dysfunction is the same in each case it appears that it may be precipitated by several clinical entities.

There are clear clinical implications implicit in this entity described by Gass, in that widespread visual field loss in the presence of multifocal discrete chorioretinal lesions does not necessarily indicate the presence of optic nerve or intracranial disease. Undertaking electroretinography in such circumstances may avoid unnecessary investigations, and, may become important if appropriate therapy is identified. The role of systemic or local steroids in the treatment of AZOOR is not clear. Two patients with marked vitritis in this series were treated with steroids; the inflammatory signs regressed, but the visual field failed to improve in both.

F.G.H. was supported by the Gertrud-Kusen-Foundation, Hamburg, Germany, grant Ho92/93-01-2. R.Y.K. was supported by the National Retinitis Pigmentosa Foundation, Baltimore, Maryland, USA. S.D.S. was partially supported by the Ahmanson Foundation, Los Angeles, California, USA.

Key words: Acute zonal occult outer retinopathy. Multifocal choroiditis, Punctate inner choroidopathy.

\section{REFERENCES}

1. Gass JDM. Acute zonal occult outer retinopathy. Neurophthalmology (in press).

2. Fletcher WA, Imes RK, Goodman D, Hoyt WF. Acute idiopathic blind spot enlargement: a big blind spot syndrome without optic disc edema. Arch Ophthalmol 1988;106:44-9.

3. Jampol LM, Sieving PA, Pugh D, et al. Multiple evanescent white dot syndrome. I. Clinical findings. Arch Ophthalmol 1984; 102:671-4.

4. Hamed LM, Glaser JS, Gass JDM, Schatz NJ. Protracted enlargement of the blind spot in multiple evanescent white dot syndrome. Arch Ophthalmol 1989;107:194-8.

5. Callanan DC, Gass DM. Multifocal choroiditis and choroidal neovascularisation associated with the multiple evanescent white dot and acute idiopathic blind spot enlargement syndrome. Ophthalmology 1992;99:1678-85.

6. Khorram KD, Jampol LM, Rosenberg MA. Blind spot enlargement as a manifestation of multifocal choroiditis. Arch Ophthalmol 1991;109:1403-7.

7. Bos PJM, Deutman AF. Acute macular neuroretinopathy. Am J Ophthalmol 1975;80:573-84.

8. Fountain JA, Schlegel TF. Linear streaks of the equator in the presumed ocular histoplasmosis syndrome. Arch Ophthalmol 1981;99:246-8.
9. Krill AE, Chishti MI, Klein BA. Multifocal inner choroiditis. Trans Am Acad Ophthalmol Otolaryngol 1969;73: $222-42$.

10. Morgan CM, Schatz H. Recurrent multifocal choroiditis. Ophthalmology 1986;93:1138-47.

11. Dreyer FR, Gass DM. Multifocal choroiditis and panuveitis: a syndrome that mimics ocular histoplasmosis. Arch Ophthalmol 1984; 102:1776-84.

12. Delayre T, Soubrane G, Ramahefasolo C, Coscas G. Multifocal choroiditis: diagnostic aspects and results of photocoagulation. J Fr Ophtalmol 1989;12:97-102.

13. Archer DB, Maguire CJF, Newell FW. Multifocal choroiditis. Trans Ophthalmol Soc UK 1974;95:184-91.

14. Doran RML, Hamilton AM. Disciform macular degeneration in young adults. Trans Ophthalmol Soc UK 1982;102: 471-80.

15. Palestine An Nussenblatt R, Parver L, Knox D. Progressive subretinal fibrosis and uveitis. Br J Ophthalmol 1984;68: 667-73.

16. Watzke RC, Packer AJ, Folk JC, Benson WE, Burgess D, Ober RR. Punctate inner choroidopathy. Am J Ophthalmol 1984;98:572-84.

17. Flage T, Bratberg A, Syrdalen P. Haemorrhagic maculopathy in young adults. Acta Ophthalmol (Copenh) 1977;55: 489-96.

18. Gass JDM, Wilkinson CP. Follow-up study of presumed ocular histoplasmosis. Trans Am Acad Ophthalmol Otolaryngol 1972;756:672.

19. Gutman FA. The natural course of active choroidal lesions in the presumed ocular histoplasmosis syndrome. Trans Am Ophthalmol Soc 1979;777:515-41.

20. Klein ML, Fine SL, Knox DL, Patz A. Follow-up study in eyes with choroidal neovascularisation caused by presumed ocular histoplasmosis. Am J Ophthalmol 1977;83:830-5.

21. Elliott JH, Jackson DJ. Presumed histoplasmatic maculopathy: clinical course and prognosis in nonphotocoagulated eyes. Int Ophthalmol Clin 1975;15:29-39.

22. Watzke RC, Claussen RW. The long-term course of multifocal choroiditis (presumed ocular histoplasmosis). Am J Ophthalmol 1981;91:750-60.

23. Gass JDM. Stereoscopic atlas of macular disease: diagnosis and treatment, 3rd ed. Vol. 2. St Louis: CV Mosby, 1987: 536-7.

24. Eldem B, Cumhur S. Punctate inner choroidopathy and its differential diagnosis. Ann Ophthalmol 1991;23:153-8.

25. Tiedeman JS. Epstein-Barr viral antibodies in multifocal choroiditis and panuveitis. Am J Ophthalmol 1987;103: 659-63.

26. Spaide RF, Sugin S, Yannuzzi LA, DeRosa JT. Epstein-Barr virus antibodies in multifocal choroiditis and panuveitis. Am J Ophthalmol 1991;112:410-3.

27. Roth AM. Histoplasma capsulatum in the presumed ocular histoplasmosis syndrome. Am J Ophthalmol 1977;84: 293-9.

28. Scheider A. Multifocal inner choroiditis. Germ J Ophthalmol 1993;2:1-9. 